\title{
49,XXXXY Syndrome with Autoimmune Diabetes and Ocular Manifestations
}

\author{
Baris Onder Pamuk ${ }^{\mathrm{a}}$ Ayse Nur Torun ${ }^{\mathrm{a}}$ Mustafa Kulaksizoglu ${ }^{\mathrm{a}}$ Cengiz Algan ${ }^{\mathrm{b}}$ \\ Derun Taner Ertugrul ${ }^{\mathrm{a}}$ Zerrin Yilmaz ${ }^{\mathrm{c}}$ Neslihan Bascil Tutuncu ${ }^{\mathrm{a}}$ \\ Nilgun Guvener Demirag ${ }^{a}$ \\ Departments of ${ }^{a}$ Endocrinology and Metabolism, ${ }^{b}$ Ophthalmology and ${ }^{c}$ Medical Genetics, Faculty of Medicine, \\ Baskent University, Ankara, Turkey
}

\section{Key Words}

49, XXXXY syndrome $\cdot$ Autoimmune diabetes $\cdot$ Cataract .

Glaucoma

\begin{abstract}
Objective: We report a rare case of $49, \mathrm{XXXXY}$ syndrome with autoimmune diabetes (requiring insulin therapy), bilateral cataracts and unilateral glaucoma. Clinical Presentation and Intervention: A 25-year-old man with mental retardation presented with multiple skeletal abnormalities, polyuria and polydipsia. He had high glucose concentrations, without ketonuria, and hypergonadotropic hypogonadism. Ophthalmic examination revealed a polar cataract in both eyes and increased intraocular pressure in the left eye. The antiislet cell antibody test was positive, and anti-glutamic acid decarboxylase autoantibody levels were elevated. Karyotype analysis revealed 49,XXXXY. Intensive insulin therapy and testosterone replacements were started. Conclusion: The autoimmune nature of diabetes that we observed in our patient seems to be predisposed by hypogonadism. Cataract and glaucoma in this case seem to be the result of diabetes, and an association of these ocular manifestations with the syndrome 49,XXXXY seems unlikely.
\end{abstract}

Copyright $\odot 2009$ S. Karger AG, Base

\section{KARGER}

Fax +41613061234 E-Mail karger@karger.ch www.karger.com
(C) 2009 S. Karger AG, Basel

$1011-7571 / 09 / 0186-0482 \$ 26.00 / 0$

Accessible online at:

www.karger.com/mpp

\section{Introduction}

First described by Fraccaro et al. [1], 49, XXXXY syndrome is a rare disorder with an incidence of 1 in 85,000 male births. The classical phenotype of this syndrome includes mental retardation, radioulnar synostosis and hypogonadism [2]. In 1942, Klinefelter et al. [3] described a syndrome in which postpubertal males demonstrated tall stature, infertility, gynecomastia and lack of pubertal virilization, testicular failure, azoospermia, elevated gonadotropin levels and decreased 17-ketosteroid levels, but it was not until 1959 that Jacobs and Strong [4] confirmed that these males had a chromosomal disorder with an extra $\mathrm{X}$ chromosome. Males with more than 1 extra sex chromosome (e.g. 48,XXYY, 48,XXXY, 49,XXXXY) are diagnosed with Klinefelter syndrome variants. They are not common, and have distinctive physical and behavioral features. Klinefelter syndrome has come to encompass the variants as well as the more common 47,XXY chromosome variation. Patients with $49, \mathrm{XXXXY}$ syndrome have a distinct appearance, including characteristic facial features, cardiac defects, multiple skeletal anomalies, abnormalities of the genitalia, mental deficiency and speech problems, which have not been reported in Klinefelter syndrome patients [2]. In this report, we present a rare case of pentasomy 49,XXXXY complicated

Tel. +90 312212 2912, Fax +90 312215 4216, E-Mail bopamuk@yahoo.com 
Fig. 1. The patient's appearance on frontal (a) and lateral (b) views.

Fig. 2. The pale optic disc observed on funduscopy.
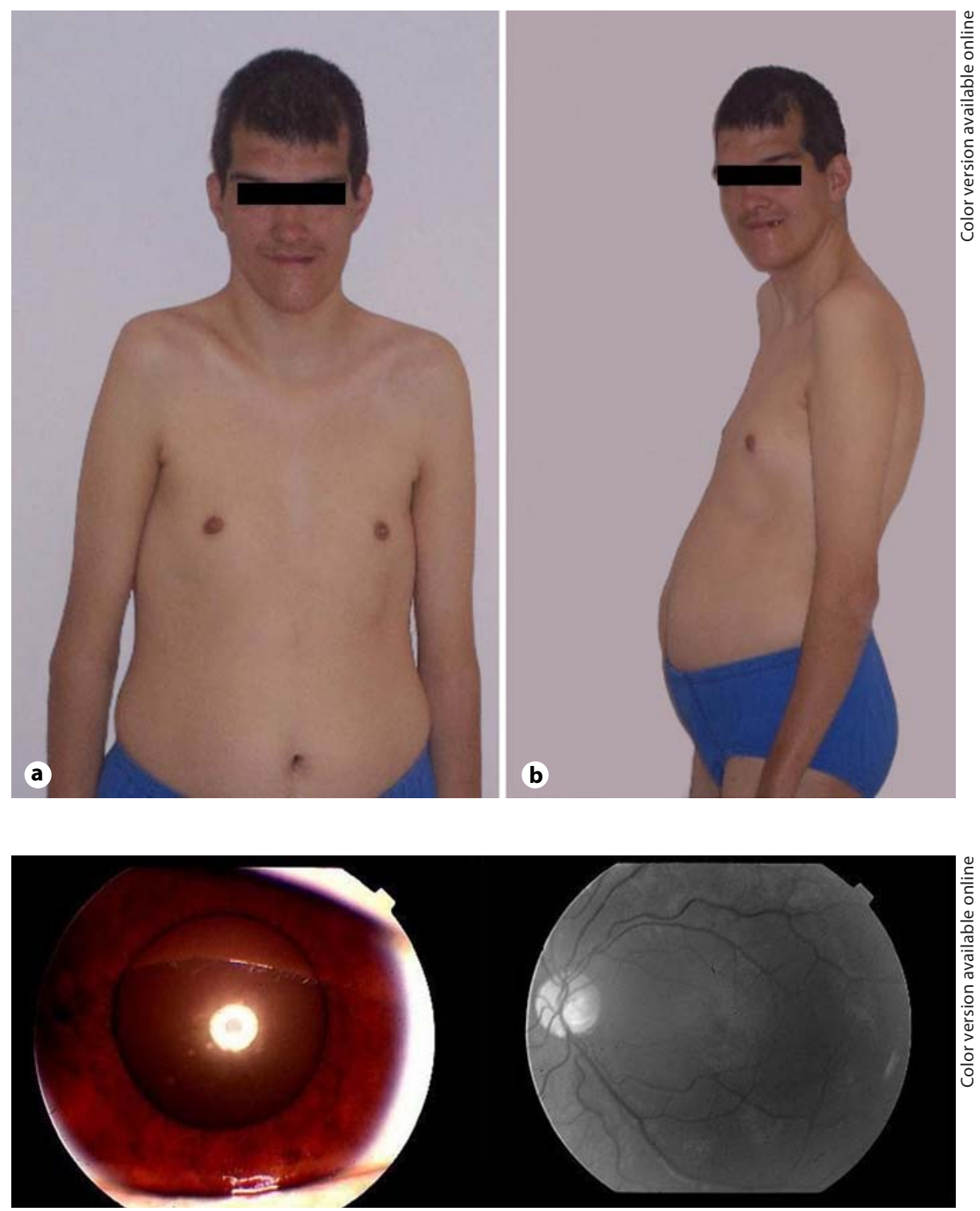

with autoimmune diabetes, cataract and glaucoma. To our knowledge the combination of these features in 49 , XXXXY syndrome has not been reported before.

\section{Case Report}

A 25-year-old man with mental retardation was referred for an evaluation of diabetes. On his previous admission, he presented with polyuria and polydipsia, high fasting plasma glucose concentrations (352-400 mg/dl) without ketonuria, and needed insulin therapy. However, insulin was withdrawn due to recurrent hypoglycemic episodes, and he was referred to our hospital. The patient is the first child of the nonconsanguineous parents. His little brother was healthy, without a remarkable medical history.
At birth, his mother was 25 and his father was 28 years old. He was born via spontaneous vaginal delivery at term. His birth records are unknown, but his mother recognized delayed mental and motor development of her child when compared with contemporary infants. On admission, he was $192 \mathrm{~cm}$ tall (90th percentile) and weighed $75 \mathrm{~kg}$ (75th to 90th percentile). He had a characteristic facial appearance with prognathism, widened nasal bridge and strabismus. His elbow rotation was limited bilaterally. He had atrophic testes with micropenis. The rest of the physical examination findings were normal (fig. 1). Ophthalmic examination revealed a polar cataract in both eyes, and the increased intraocular pressure in the left eye was $26 \mathrm{~mm} \mathrm{Hg}$. Funduscopic examination showed left optic atrophy (fig. 2).

Results of the complete blood count and biochemical analysis are given in table 1 . Since the basal cortisol level was low with a normal ACTH level, a short ACTH stimulation test was per- 
Table 1. Blood count and biochemical analysis

Patient's result

Complete blood count

RBC (4.5-5.8 million), cells/ $\mu \mathrm{l}$

$\mathrm{Hb}(13.5-18), \mathrm{g} / \mathrm{dl}$

Hematocrit (36-50), \%

4.45 million

12

35.9

Platelet count (150,000-400,000), cells/ $\mu \mathrm{l}$

Mean corpuscular volume (80-96), fl

183,000

81.3

Blood biochemistry

Fasting plasma glucose (70-100), mg/dl 326

Postmeal plasma glucose (60-140), mg/dl 416

$\mathrm{Hb}_{\mathrm{A} 1 \mathrm{C}}(4-6), \%$

LDL cholesterol (60-130), mg/dl 73

HDL cholesterol (30-70), mg/dl 25

Lipoprotein(a) (0-29), mg/dl 1.8

Iron (50-140), $\mu \mathrm{g} / \mathrm{dl}$

Total iron-binding capacity (150-350), $\mu \mathrm{g} / \mathrm{dl} 281$

Ferritin (20-300), ng/ml

91.6

Urinalysis

Protein $(0-25), \mathrm{mg} / \mathrm{dl}$

24-hour urinalysis

Protein (0-150), mg/day

Microalbuminuria (30-300), mg/day

247

$\mathrm{C}_{\mathrm{Cr}}(90-140), \mathrm{ml} / \mathrm{min}$

17.74

139.1

formed, which revealed a normal cortisol response. His folliclestimulating hormone level was elevated at $38.21 \mathrm{mIU} / \mathrm{ml}$ (normal range: $0.7-11.4 \mathrm{mIU} / \mathrm{ml}$ ), luteinizing hormone was elevated at $37.56 \mathrm{mIU} / \mathrm{ml}$ (normal range: $1.7-8.6 \mathrm{mIU} / \mathrm{ml}$ ) and free testosterone was low at $5.43 \mathrm{pg} / \mathrm{ml}$ (normal range: $10-42 \mathrm{pg} / \mathrm{ml}$ ); these results were consistent with primary hypogonadism. Anti-islet cell antibody was positive (normal range: negative) and anti-glutamic acid decarboxylase (GAD) autoantibody level was elevated at 1.2 $\mathrm{IU} / \mathrm{ml}$ (normal range: 0-1 IU/ml). His karyotype analysis revealed 49,XXXXY. Echocardiography and ultrasonography of the abdomen were both unremarkable. An X-ray of the elbow joints showed bilateral radioulnar synostosis. His hyperglycemia necessitated constant intensive insulin therapy. After achievement of blood glucose control, he also required testosterone replacement therapy for primary hypogonadism.

\section{Discussion}

In more than 100 reported cases of $49, \mathrm{XXXXY}$ syndrome, classical features of the syndrome have included radioulnar synostosis, hypogonadism, and mental retardation [2]. The 3 extra X-chromosomes in 49,XXXXY result in the most severe variant of Klinefelter syndrome. Altered facial features are usually evident and include hypertelorism, epicanthal folds, broad nasal bridge, low-set and malformed ears, and prognathism. The neck is short

and broad, whereas the thorax is narrow. Cardiac defects are present in 15-20\% of affected individuals, and short stature, radioulnar synostosis, genu valgum, pes cavus, and hyperextensible joints are very frequent. Genitalia are usually very hypoplastic, and cryptorchidism is often presented [5]. It is estimated that each extra X-chromosome lowers the expected IQ by about 15 points, and males with 49,XXXXY have IQs ranging between 20 and 60 , and typically present with global developmental delays [2]. They have been described to be shy and friendly, with occasional temper tantrums and irritability as a result of impaired communication skills with markedly deficient expressive language [2].

To our knowledge, this report is the first case of 49, XXXXY syndrome complicated with autoimmune diabetes, cataract and glaucoma. There are 2 reported cases of 49,XXXXY syndrome with prediabetes and diabetes $[5,6]$. The case reported by Christensen and Therkelsen [6] was glucose intolerant after an oral glucose tolerance test, but not a true diabetic. Kim et al. [7] reported a diabetic 49,XXXXY case, in which insulin treatment was shifted to oral anti-diabetics and there was a positive family history for type 2 diabetes. The incidence of type 2 diabetes is reported to be high in syndromes with $\mathrm{X}$ polysomy, but a definite mechanism other than hypogonadism is unknown [8].

It appears that autoimmune diseases occur more frequently in Klinefelter syndrome. Systemic lupus erythematosus, ankylosing spondylitis, Sjögren syndrome (keratoconjunctivitis, dry mouth, and arthritis) and rheumatologic disorders have all been reported [9-11]. However, no cross-sectional or longitudinal studies have been carried out. Testosterone has been hypothesized to protect normal males from autoimmune phenomena; thus, low testosterone and high estrogen levels in Klinefelter syndrome may predispose hypogonadal males to defects in T cell activity that lead to autoimmune disorders. Diabetes is more frequent among males with $47, \mathrm{XXY}$ and their parents than in the general population $[8,12]$. An autoimmune component is likely to be responsible for type 1 diabetes mellitus, since autoantibodies against insulin and pancreatic tissue are recorded in males with 47,XXY.

However, the incidence of diabetes in X-polysomies is not known. This may be due to lack of follow-up data of the 46,XXXXY cases, because most of these cases were reported at younger ages. The diabetes in our patient is autoimmune diabetes, which differs from the reported diabetes in other 49,XXXXY cases. Insulin dependency, positive autoimmune markers such as anti-GAD, lack of 
family history, and obesity in our patient support our diagnosis. Female predominance of autoimmune diseases such as systemic lupus erythematosus suggest that sex hormones may be potential factors in the pathogenesis of these diseases [9]. There are several reports that suggest a possible relationship between autoimmunity and hypogonadism in Klinefelter's syndrome [10-12]. Bizzarro et al. [9] described 3 men with 47,XXY and Sjögren syndrome and 2 with systemic lupus erythematosus. While on oral testosterone therapy, their serum antinuclear antibody levels, sedimentation rate, and rheumatoid factor all significantly decreased and the percentage of $\mathrm{T}$ helper cells and $\mathrm{T}$ suppressor cytotoxic cells significantly increased, compared with pretreatment and placebo values. Clinical features of their autoimmune disease also were less pronounced after initiation of testosterone therapy. Men with 49,XXXXY are more hypogonadal than 47,XXY men, and this condition may have increased the risk for the autoimmune diabetes in our patient. To prove this theory, further follow up studies with 49,XXXXY cases for development of autoimmune diseases are needed.

$49, \mathrm{XXXXY}$ syndrome has some characteristic ophthalmic manifestations like strabismus, hypertelorism and epicanthal folds [13]. However, the glaucoma and cataract that we observed in our patient have not been previously reported as 49,XXXXY-related ocular findings. Cataract, which is associated with chromosomal anomalies, is usually congenital; congenital cataract is diagnosed at infancy and early childhood, and it is also frequently associated with systemic diseases, such as diabetes. Our patient did not suffer from congenital cataract, so the cataract that we observed in this patient seems to be related to diabetes. The pale optic disc reflects a longlasting glaucoma in our patient. Although it is not possible to determine the etiology of glaucoma in this patient, it may be associated with the syndrome itself or, most likely, the diabetes.

\section{Conclusion}

The autoimmune nature of diabetes that we observed in our patient seems to be predisposed by hypogonadism. Cataract and glaucoma in this case seem to be the result of diabetes, and an association of these ocular manifestations with the syndrome 49,XXXXY seems unlikely.

\section{References}

1 Fraccaro M, Kaijser K, Lindsten J: A child with 49 chromosomes. Lancet 1960;2:899902.

2 Linden MG, Bender BG, Robinson A: Sex chromosome tetrasomy and pentasomy. Pediatrics 1995;96:672-682.

>3 Klinefelter HF, Reifenstein EC, Albright F: Syndrome characterized by gynecomastia aspermatogenesis without aleydigism and increased excretion of follicle stimulating hormone. J Clin Endocrinol Metab 1942;2: 615-627.

4 Jacobs PA, Strong JA: A case of human intersexuality having a possible XXY sex-determining mechanism. Nature 1959;183:302303.

5 Visootsak J, Aylstock M, Graham JMJ: Klinefelter syndrome and its variants: an update and review for the primary pediatrician. Clin Pediatr 2001;40:639-651.
6 Christensen MF, Therkelsen AJ: A case of the XXXXY chromosome anomaly with four maternal X chromosomes and diabetic glucose tolerance. Acta Paediatr Scand 1970;59: 706-710.

7 Kim HJ, Kim D, Shin JM, Chung HK, Lee G 49,XXXXY syndrome with diabetes mellitus. Horm Res 2006;65:14-17.

$>8$ Nielsen J, Johansen K, Yde H: Frequency of diabetes mellitus in patients with Klinefelter's syndrome of different chromosome constitutions and the XYY syndrome: plasma insulin and growth hormone level after a glucose load. J Clin Endocrinol Metab 1969; 29:1062-1073.

-9 Bizzarro A, Valentini G, Di Martino G, DaPonte A, De Bellis A, Iacono G: Influence of testosterone therapy on clinical and immunological features of autoimmune diseases associated with Klinefelter's syndrome. J Clin Endocrinol Metab 1987;64:32-36.

10 Armstrong RD, Macfarlane DG, Panayi GS: Ankylosing spondylitis and Klinefelter's syndrome: does the $\mathrm{X}$ chromosome modify disease expression? Br J Rheumatol 1985;24: 277-281.
11 Kobayashi S, Shimamoto T, Taniguchi O, Hashimoto H, Hirose S: Klinefelter's syndrome associated with progressive systemic sclerosis: report of a case and review of the literature. Clin Rheumatol 1991;10:84-86.

12 Simpson JL, De La Cruz F, Swerdloff RS, Samango-Sprouse C, Shakkebaek NE, Graham JMJ, Hassold T, Aylstock M, Meyer-Bahlburg HF, Willard HF, Hall JG, Salameh W, Boone K, Staessen C, Geschwind D, Giedd J, Dobs AS, Roqol A, Brinton B, Paulsen CA: Klinefelter syndrome: expanding the phenotype and identifying new research directions. Genet Med 2003;5:460-468.

-13 Borghgraef M, Fryns JP, Smeets E, Marien J, van Den Berghe H: The 49,XXXXY syndrome: clinical and psychological follow-up data. Clin Genet 1988;33:429-434. 